\title{
Clinical Psychology in Spain: History, Regulation and Future Challenges
}

\author{
Javier Prado-Abril ${ }^{\mathrm{a}}$, Sergio Sánchez-Reales ${ }^{\mathrm{b}}$, Alberto Gimeno-Peón ${ }^{\mathrm{c}}$, \\ José Antonio Aldaz-Armendáriz ${ }^{a}$
}

[a] Department of Mental Health, Aragón Healthcare Service (Spanish National Health System), Zaragoza, Spain. [b] Department of Mental Health, Murcia Healthcare Service (Spanish National Health System), Murcia, Spain. [c] Department of Mental Health, Principality of Asturias Healthcare Service (Spanish National Health System), Gijón, Spain.

Clinical Psychology in Europe, 2019, Vol. 1(4), Article e38158, https://doi.org/10.32872/cpe.v1i4.38158

Received: 2019-07-10 • Accepted: 2019-09-25 • Published (VoR): 2019-12-17

Handling Editor: Anton-Rupert Laireiter, University of Vienna, Vienna, Austria

Corresponding Author: Javier Prado-Abril, Aragón Healthcare Service, Plaza de la Convivencia, 2, 50017 Zaragoza, Spain. E-mail: jpradoabril@gmail.com

\begin{abstract}
The heterogeneity of national regulations in clinical psychology and psychological treatment across Europe requires a detailed description of every regulation to start a shared discussion. In the current paper, we describe the history, legal regulations, a specialized training program, the current status and some future challenges for clinical psychology in Spain. The evolution of clinical psychology in the Spanish National Health System (NHS) towards a health specialty regulated by law, exemplifies a balanced process of expansion, social recognition and professional settlement. Overall, the growth of clinical psychology in Spain may depend on access to leadership and management positions in the NHS that would allow a better organization of care resources to improve citizens' access to psychological treatment.
\end{abstract}

\section{Keywords}

clinical psychology, psychological treatment, training, education, national regulation, Spain 


\section{Highlights}

- Spanish regulation of clinical psychology is mediated by socio-cultural and political changes that occurred in the late 70's and 80's in the country.

- Recognition as a licensed clinical psychologist is obtained through a 4-year training system as an intern resident psychologist (PIR).

- PIR is a training system of supervised internships, with increasing autonomy in various healthcare departments in the National Health System (NHS).

- Achieving independent Clinical Psychology Services within the NHS in order to organize, implement and deliver evidence-based practices is currently one of our biggest challenges in the near future.

Spanish clinical psychology welcomes the creation of the European Association of Clinical Psychology and Psychological Treatment (EACLIPT) and its journal Clinical Psychology in Europe (CPE). In its first issue, Laireiter and Weise (2019) reviewed and updated the heterogeneity of national regulations in clinical psychology and psychological treatment in Europe and invited European clinicians to start a discussion on the matter. As suggested by Van Broeck and Lietaer (2008), this heterogeneity is influenced at least by political issues, the organization of health care and educational aspects. This paper tries to contribute to the discussion with a description of the history, development and current status of clinical psychology in Spain.

\section{A Brief History of Clinical Psychology in Spain}

Spain endured a dictatorship from the end of our Civil War (1936-1939) until 1975. The subsequent democratization process ushered in a series of key events, the appreciation of which is necessary in order to understand the development of clinical psychology as a health specialty in our country. In 1978, the new democratic constitution stated in Article 43 that Spaniards should be entitled to health protection. More specifically, the constitution emphasized that public authorities should provide appropriate measures to assist people with mental health problems. In 1986, the General Health Law (Law 14/1986) developed the constitutional mandate and established the basis of a public National Health System (NHS). From the very beginning, governmental policies tried to develop the highest healthcare standards and welfare benefits for our citizens. Likewise, the key element of quality of care became the responsibility of health specialists who had to meet strict and demanding training programs (Sánchez-Reales, Prado-Abril, \& Aldaz-Armendáriz, 2013).

Simultaneously, so-called Psychiatric Reform in 1985 brought about a significant change in psychiatric care policies in Spain: (i) the development of new mental health management structures with an extensive community network of outpatient mental 
health centers, (ii) the integration of care for psychiatric patients into the general health care system, and (iii) the adoption of an interdisciplinary clinical approach (VázquezBarquero \& García, 1999). Interdisciplinary mental health teams allowed psychologists to gradually become part of mental health units in the newly created NHS. At the same time, new faculties of psychology opened in several Spanish universities (Olabarría \& García, 2011). Prior to this, psychologists did not receive a specific education or bachelor's degree in psychological science. They used to graduate with a philosophy and letters degree and obtained a mention in psychology after following a certain academic trajectory. The institutionalization of psychology was then at its infancy. In the meantime, the NHS created its own training system in the early 80's mainly for medical specialties (Royal Decree [RD] 127/1984). The training of health specialists was now entrusted to the NHS rather than universities or other educational institutions. Specialized training now fell under the auspices of the NHS and regulated and exclusively controlled by central government (Olabarría \& García, 2011; Sánchez-Reales et al., 2013). Specialties were to be approved by RD at the proposal of the ministries of health and education (RD 639/2014), and competence in non-specialized education was left to universities alone (Prado-Abril, Sánchez-Reales, \& Aldaz-Armendáriz, 2014).

From 1986 until late into the first decade of the $21^{\text {st }}$ century, Spain experienced a political process of decentralization. Nowadays, health care is provided by Autonomous Regional Governments (ARG). They manage health care plans and are the main public health care providers. Nonetheless, certain national controls are preserved to guarantee equal access to NHS services and healthcare assistance (Law 16/2003). Some ARG assumed health competences before others. These regions pioneered training programs in clinical psychology. These training programs followed the training model that was already established for medical specialties based on internship and placements. The Principality of Asturias was the first ARG to promote a clinical psychology training program in 1983 (García Solar et al., 1986). Andalusia and Castile-Leon in 1986 and Navarre in 1988 followed (Aparicio, 1990). Training was based on several supervised internships on different mental health placements in hospitals and other public health services. This was professionalizing and remunerated employment. Trainees were allowed increasing clinical autonomy and responsibilities during the three-year training.

In 1993, the first national call took place once regional trial programs were considered successful (Olabarría, 1998). Access to training was based on a national psychology test. Since then, the PIR test call (for its acronym in Spanish, test of access to specialized health training as intern resident psychologist) has taken place every year. Access is based on principles of equality, merit and ability (e.g., Ministerial Order SCB/947/2018). Later, in 1998, the title of psychologist specialized in clinical psychology (RD 2490/1998) was created and regulated after a complex process of political and professional negotiations (ANPIR, 2018). This RD regulates the health specialty in clinical psychology and es- 
tablishes the PIR system as the only way to obtain this title. However, a transitory homologation process was established for practicing psychologists.

Currently, it is estimated that there could be up to 9,000 clinical psychologists in our country although there is no official register in Spain as yet (Duro, 2019). As for other health professionals, there are probably three psychiatrists for each clinical psychologist if we take into account that there are twice as many training posts per year for psychiatrists and their specialized education began some years before ours. Psychotherapy is not a regulated health profession. However, the Ministry of Health has launched a National Register of Health Professionals ${ }^{1}$. This will enable us to know, in the near future, the exact number of professionals in each of the regulated Health Specialties.

The process by which clinical psychology became a health specialty regulated by law (RD 2490/1998), with similar administrative, organizational and competence status as medical specialties (Law 44/2003), shows how a balanced approach of growth, social recognition and professional settlement took place in Spain over the past three decades. This was a process that also suffered socio-political, economic, and organizational constraints some of which came from professional psychology corporations (Olabarría, 1998;

Olabarría \& García, 2011; Sánchez-Reales et al., 2013). Therefore, the presence of clinical psychology in the NHS is intimately related to the process of democratization in Spain. Legally regulated tasks such as (clinical) assessment, diagnosis, (psychological) treatment, management and team leadership were now recognized as part of the scope of roles of clinical psychologists within the NHS. Clinical psychologists now hold full professional autonomy and clinical responsibility without interference from any other health professionals and enjoy a similar legal status to any other health specialty (Law 44/2003) such as, for example, psychiatrists or neurologists.

\section{PIR Test Access, PIR Training System and Psychologist Specialized in Clinical Psychology}

Nowadays, clinical psychology is structured in three different stages: bachelor's degree in psychology (4 years and 240 ECTS), non-academic postgraduate specialized training (PIR), and continuing education (CE) for specialists or independent practice as psychologists specialized in clinical psychology (Law 44/2003). However, other educational trajectories which can improve basic health training are currently under discussion (GonzálezBlanch, 2015; Prado-Abril et al., 2014; Sánchez-Reales et al., 2013). Specifically, the socalled degree-Master-PIR itinerary is being proposed as the standard access to the PIR exam call from a Master's degree level of university education. This sequential education could be useful to support the progressive acquisition of skills and competences from lower to higher level of expertise. Similarly, it would foster a needed mutual understand-

1) https://www.mscbs.gob.es/profesionales/registroEstatal/home.htm 
ing and collaboration between academics and clinicians. It may also promote a reduction in the gap between research and practice.

PIR posts are annually announced by the Ministry of Health (141 vacancies this 2019; Ministerial Order SCB/947/2018) and psychologists, who have finished their undergraduate education, can apply. The exam usually takes place around February every year. Those who obtain the best scores can opt for different training placements throughout the NHS and begin their PIR specialized training (Tables 1, 2) in May.

Table 1

PIR Specialized Training: Distribution and Duration of Supervised Internships Periods

\section{Training Program}

Duration (in months)

(P1) Community care, outpatient mental health and primary care support 12

(P2) Primary care $\quad 3$

(P3) Addictions $\quad 4$

(P4) Psychosocial rehabilitation and recovery $\quad 6$

(P5) Acute psychiatric ward, hospitalization and emergencies $\quad 4$

(P6) Clinical health psychology and liaison $\quad 6$

(P7) Child and adolescent clinical psychology $\quad 6$

(P8) Specific training areas $\quad 4$

(P9) Free disposal 3

Note. Source: Order SAS/1620/2009, https:/www.boe.es/boe/dias/2009/06/17/pdfs/BOE-A-2009-10107.pdf

Table 2

Organization and Annual Planning

\begin{tabular}{|c|c|c|c|c|c|c|c|c|c|c|c|c|}
\hline M1 & M2 & M3 & M4 & M5 & M6 & M7 & M8 & M9 & M10 & M11 & M12 & \multirow{2}{*}{ R1 } \\
\hline \multicolumn{12}{|c|}{ (P1) Community care, outpatient mental health and primary care support } & \\
\hline M13 & M14 & M15 & M16 & M17 & M18 & M19 & M20 & M21 & M22 & M23 & M24 & \multirow{2}{*}{$\mathrm{R} 2$} \\
\hline \multicolumn{3}{|c|}{ (P2) Primary care } & \multicolumn{4}{|c|}{ (P3) Addictions } & \multicolumn{5}{|c|}{ (P4) Psychosocial rehabilitation and recovery } & \\
\hline M25 & M26 & M27 & M28 & M29 & M30 & M31 & M32 & M33 & M34 & M35 & M36 & \multirow{2}{*}{ R3 } \\
\hline (P4 cont.) & \multicolumn{4}{|c|}{ (P5) Ward, hospitalization, emergencies } & \multicolumn{6}{|c|}{ (P6) Clinical health psychology and liaison } & $(\mathrm{P} 7)$ & \\
\hline M37 & M38 & M39 & M40 & M41 & M42 & M43 & M44 & M45 & M46 & M47 & M48 & \multirow{2}{*}{$\mathrm{R} 4$} \\
\hline \multicolumn{5}{|c|}{ (P7 cont.: Child and adolescent clinical psychology) } & \multicolumn{4}{|c|}{ (P8) Specific training areas } & \multicolumn{3}{|c|}{ (P9) Free disposal } & \\
\hline
\end{tabular}

Note. M1, M2, etc. = Month 1, Month 2, etc.; R1, R2, etc. = 1st year Intern Resident Psychologist (PIR), 2nd year PIR, etc.; P1, P2, etc. = Training program 1, Training program 2, etc. $($ see Table 1$)$; cont. = Continued. Source: Order SAS/1620/2009, https://www.boe.es/boe/dias/2009/06/17/pdfs/BOE-A-2009-10107.pdf

Training lasts 4 years. The exam consists of a psychology general knowledge test with 225 items (plus 10 reserve items) with a 4-option multiple-choice system. Testers have 5 hours to complete the exam. The test is composed of an open list of topics including all the contents of the psychology degree. However, a higher percentage of questions are 
taken from psychopathology, clinical and health psychology, psychological treatment, psychotherapy, psychological assessment and personality and individual differences. The final score is calculated from a formula whereby $90 \%$ of the score is obtained from the exam and $10 \%$ from the academic record.

It is a very demanding access test since there are thousands of applicants and only 189 estimated vacancies for 2020 (Source: Ministry of Health). Only one study has evaluated the characteristics of the applicants that obtain a placement (Carreras \& Morilla, 2010). Using a survey completed by 61 out of the 131 intern resident psychologists that began their training in 2010, authors found that the test preparation phase involved an average of 16.11 months of full-time study, with an average 7 study hours a day and a total amount of 2,881 hours before the exam. This scenario contrasts with the number of vacancies offered at degree level by academic institutions that draws an excessive and irresponsible formative bubble that leaves a structural unemployment of 20,000 non-specialist psychologists (Sánchez-Reales et al., 2017). The need to restrict access at degree level and the development of a sustainable profession as a whole is a national controversy that exceeds the purposes of this paper, but is outlined in Sánchez-Reales et al. (2017).

Regarding the PIR specialized training, Article 21 (Law 44/2003) establishes the procedure to approve the training programs of the Health Specialties. The National Commission of the Specialty in Clinical Psychology (NCSCP) elaborated and proposed the current training program in 2009 (Tables 1, 2). Since the NCSCP is an advisory committee, the training program was then ratified by the National Council of Specialties in Health Sciences of the Ministries of Health and Education (Order SAS/1620/2009).

Consequently, after passing the PIR test and choosing one of the NHS vacancies, trainees are enrolled at a hospital teaching unit of psychiatry and clinical psychology. This teaching unit will ensure compliance with the program for 4 years. In addition, trainees sign a full-time contract of 37.5 hours a week. They become full members of staff at the health area to which they are attached. Their income is around 15,400-22,400 € before tax per year depending on different incentives (RD 1146/2006). Their clinical practice is supervised by staff clinical psychologists assuming increasing clinical responsibility and professional autonomy over the 4 years of training.

This training system fundamentally provides skills and competences to future clinical psychologists for a performance in clinical and healthcare settings. It basically provides skills and legal competence for clinical assessment, diagnosis and psychological treatment (Order SAS/1620/2009). However, as a theoretical-technical program, and in coherence with the EACLIPT Task Force proposal (2019), the training program goes further and establishes four main thematic areas: (i) co-education and training, with other specialists in health sciences (doctors, pharmacists, biologists, chemists), in bioethics and professional deontology, healthcare organization and management, health legislation, and research methods; (ii) general theoretical education in clinical psychology (e.g., clinical sessions, seminars, specific training in psychotherapy schools); (iii) clinical and 
healthcare contents or different internships (Table 1); and (iv) continuing care. Therefore, as part of future professional challenges, clinical psychologists are enabled for healthcare policy management and leadership of mental healthcare services. Nonetheless, most management posts are occupied nowadays by physicians and psychiatrists. The training program also promotes teaching and research and many residents complete their academic $\mathrm{PhD}$ during their training or shortly after finishing it.

As in other European countries, there is a close relationship between training in clinical psychology and psychotherapy, which requires a more detailed explanation. First, clinical psychology holds a broader scope than psychotherapy. Despite the progressive expansion of the integrative approach, psychotherapy continues to be a set of schools and name brands (or acronym-defined treatments) with epistemological, theoretical and technical differences sometimes irreconcilable (Paris, 2013). Instead, clinical psychology in Spain was designed from the very beginning, taking inspiration from the Boulder Model (1949; cited in Frank, 1984) in order to promote an atheoretical training that combined scientific knowledge with the delivery of professional service mainly from a public health care stance (Ávila Espada, 1990). Right now, we can perhaps say that PIR training is a pluralistic and free-school education system, although subject to the requirements of evidence-based practice (American Psychological Association [APA], 2006). Likewise, in licensed clinical psychologists, although they should follow clinical guidelines, integrative attitudes prevail as shown in a recent national survey (Prado-Abril et al., under review).

It is important to emphasize that training in clinical psychology lays the groundwork for a clinical psychologist to face clinical practice in Spain with a broad view (EACLIPT Task Force On "Competences of Clinical Psychologists", 2019). Future sub-specialization may be required in certain mental health settings. We are aware that our PIR training system may seem long and excessive in certain European countries. However, it has been emphasized that excellence is a goal in the NHS (Law 14/1986) and this is based on having well trained health specialists. From that viewpoint, some contents that appear in Table 1 may be better understood. The specific training areas that clinical psychologists pursue could be sub-specialized into psycho-oncology and palliative care, neuropsychology, psychogeriatrics, sexual and reproductive health, eating disorders, personality disorders or extend 4 more months in child and adolescent clinical psychology, among other options. The Free Disposal internship placement reinforces this strategy and it allows for a placement in an international mental health institution or in accredited excellence healthcare settings, while keeping their salary. The most common destinations are the United States, Argentina and the United Kingdom (UK). ANPIR society offers scholarships to the best candidates and a list of some of the centers chosen in recent years can be seen in https://www.anpir.org/becas-anpir/. Finally, continuing care is a very important part of the program since it allows a supervised continued clinical activity throughout the 4 years of training allowing a broader view of clinical practice that sometimes can 
be limited by short-term specific internships. Continuing care is carried out in different ways such as the performance of low and high-intensity psychological treatments in individual and/or group formats, both in outpatient mental health centers or primary care, liaison programs (in oncology, neurology...) or even, taking part in emergency guards with their psychiatry co-residents.

\section{Conclusions and Future Challenges}

In the last 26 years, clinical psychology in Spain has progressively acquired its own identity based on a solid specialized health training that also has a clear interest in contributing to the development of high-quality public health services. However, Spanish clinical psychology faces some important future challenges.

The two main future challenges are improving training and citizens' access to psychological treatments within the NHS. Concerning training, there are suggestive evidence-based proposals on how to improve supervision and a more individual-focused training (Callahan \& Watkins, 2018; Prado-Abril, Gimeno-Peón, Inchausti, \& SánchezReales, 2019). Once training in evidence-based treatments is established, it is crucial to promote those personal and interpersonal attitudes and skills that have proven to influence the outcome of psychological treatments (Bennett-Levy, 2019; Heinonen \& NissenLie, 2019). The goal is to get our specialists to be flexible while remaining faithful to wellestablished procedures (Norcross \& Wampold, 2018; Truijens, Zühlke-van Hulzen, \& Vanheule, 2019) and involved in CE throughout their professional life.

The second goal is perhaps somewhat more complicated but inspired by the UK experience (Clark, 2018). Primary care-mental health interface programs and stepped care models should be implemented and developed so as to improve access to well-established psychological treatments. This would allow a better management of common mental health disorders that otherwise do not receive adequate treatment and reducing the mental disorders burden charge (Ruiz-Rodríguez et al., 2018). Catalonia has pioneered this strategy since 2006, so by 2017 all mental health programs in primary care were available for the entire Catalonian territory. The rest of the country is still far behind, but the PsicAP Project (Psicología en Atención Primaria [Psychology in Primary Care]; e.g., González-Blanch et al., 2018; Ruiz-Rodríguez et al., 2018) is gradually helping to change the mindset of health and policy managers. PsicAP is a national multicentric randomized controlled trial that pursues testing the effectiveness, cost-effectiveness and cost-utility of a transdiagnostic cognitive-behavioral group therapy versus treatment as usual with common mental health disorders in the primary care settings (Cano-Vindel et al., 2016).

Other specific challenges that derive from these two major issues listed above are now going to be summarized. In order to carry out a solid and professional mental health care project, we will not only need better trained professionals, but also a greater number of them and, consequently, more than 141 or 189 PIR vacancies per year. Similarly, devel- 
oping child prevention and care requires a greater sub-specialization. The creation and regulation of a child and adolescent clinical psychology specialty is being considered at this moment (source: Ministry of Health). It will enable clinicians to offer more effective care to children and adolescents. Likewise, there is increasing interest in strengthening training in specific areas such as neuropsychology. Nevertheless, there is still a lot of reluctance in certain healthcare contexts of the NHS regarding the development and consolidation of clinical psychology, particularly in management or leadership positions. At this point, it should be outlined that the Psychiatric Reform was an incomplete process due to a counter-reform led by some psychiatrists that gave way, at times to authoritarian, pharmaco-centric biomedical approaches. Under these limitations, our attachment to psychiatry services does not make sense anymore. There is now an increasing demand amongst clinical psychologists to create clinical psychology services. It would allow clinical psychologists to improve service delivery, management and clinical programs based on evidence-based practices without the limitations of a biomedical model that now controls care policies in mental health in Spain, limiting access to proper psychological treatment.

Funding: The authors received no financial support for the research, authorship, and/or publication of this article.

Competing Interests: JPA, SSR and AGP are members of the Board of Directors of the Spanish National Association of Clinical Psychologists and Intern Resident Psychologists (Asociación Nacional de Psicólogos Clínicos y Residentes, ANPIR).

Acknowledgments: The authors have no support to report.

\section{References}

ANPIR. (2018, November 23). 20th Anniversary of the Specialty in Clinical Psychology: Summary act [Video file]. Retrieved from https://www.youtube.com/watch?v=zl6JoQY9nPw American Psychological Association (APA). (2006). Evidence-based practice in psychology. American Psychologist, 61, 271-285. https://doi.org/10.1037/0003-066X.61.4.271

Aparicio, V. (1990). PIR: La experiencia en Asturias (1983-1989) [PIR: The experience in Asturias (1983-1989)]. Papeles del Psicólogo, 43. Retrieved from http://www.papelesdelpsicologo.es/resumen?pii=436

Ávila Espada, A. (1990). Psicología Clínica: Una formación para psicólogos especialistas en cuanto profesionales de la salud [Clinical psychology: A training for specialized psychologists as health professionals]. Papeles del Psicólogo, 43. Retrieved from http://www.papelesdelpsicologo.es/resumen?pii=431 
Bennett-Levy, J. (2019). Why therapists should walk the talk: The theoretical and empirical case for personal practice in therapist training and professional development. fournal of Behavior and Experimental Psychiatry, 62, 133-145. https://doi.org/10.1016/j.jbtep.2018.08.004

Callahan, J. L., \& Watkins, C. E., Jr. (2018). Evidence-based training: The time has come. Training and Education in Professional Psychology, 12, 211-218. https://doi.org/10.1037/tep0000204

Cano-Vindel, A., Muñoz-Navarro, R., Wood, C. M., Limonero, J. T., Medrano, L. A., . . Santolaya, F. (2016). Transdiagnostic cognitive behavioral therapy versus treatment as usual in adult patients with emotional disorders in primary care setting (PsicAP study): Protocol for a randomized controlled trial. FMIR Research Protocols, 5, Article e246. https://doi.org/10.2196/resprot.6351

Carreras, B., \& Morilla, I. (2010). Estudio sobre el examen PIR [Study on the PIR test]. Retrieved from http://www.persever.es/

Clark, D. M. (2018). Realizing the mass public benefit of evidence-based psychological therapies: The IAPT program. Annual Review of Clinical Psychology, 14, 159-183. https://doi.org/10.1146/annurev-clinpsy-050817-084833

Duro, J. C. (2019, June 18). ¿Cuántas/os Psicólogas/os Especialistas en Psicología Clínica hay en España? [How many psychologists specialized in clinical psychology are in Spain?] [Blog post]. Psychology Blog of the Official College of Psychologists of Madrid. Retrieved from http://www.copmadrid.org/wp/cuantas-os-psicologas-os-especialistas-en-psicologia-clinicahay-en-espana/

EACLIPT Task Force On "Competences of Clinical Psychologists". (2019). Competences of clinical psychologists. Clinical Psychology in Europe, 1, Article e35551.

https://doi.org/10.32872/cpe.v1i2.35551

Frank, G. (1984). The Boulder Model: History, rationale, and critique. Professional Psychology: Research and Practice, 15, 417-435. https://doi.org/10.1037/0735-7028.15.3.417

García Solar, M. L., Pascual, J., Coto, E., del Pozo, J. A., Cabero, A., \& Ripodes, P. (1986). Experiencia PIR en Asturias [PIR Experience in Asturias]. Papeles del Psicólogo, 27. Retrieved from http://www.papelesdelpsicologo.es/resumen?pii=289

González-Blanch, C. (2015). Clinical psychology after the PGS (General healthcare psychology) in Spain: A reasoned proposal. Papeles del Psicólogo, 36, 9-18. Retrieved from http://www.papelesdelpsicologo.es/English/2485.pdf

González-Blanch, C., Hernández-de-Hita, F., Muñoz-Navarro, R., Ruiz-Rodríguez, P., Medrano, L. A., Moriana, J. A., . . PsicAP Research Group. (2018). Domain-specific associations between disability and depression, anxiety, and somatization in primary care patients. Psychiatry Research, 269, 596-601. https://doi.org/10.1016/j.psychres.2018.09.007

Heinonen, E., \& Nissen-Lie, H. A. (2019). The professional and personal characteristics of effective psychotherapists: A systematic review. Psychotherapy Research. Advance online publication. https://doi.org/10.1080/10503307.2019.1620366

Laireiter, A.-R., \& Weise, C. (2019). The heterogeneity of national regulations in clinical psychology and psychological treatment in Europe: Where are we coming from, where are we now, and 
where are we going? Clinical Psychology in Europe, 1(1), Article e34406.

https://doi.org/10.32872/cpe.v1i1.34406

Norcross, J. C., \& Wampold, B. E. (2018). A new therapy for each patient: Evidence-based relationships and responsiveness. Fournal of Clinical Psychology, 74, 1889-1906. https://doi.org/10.1002/jclp.22678

Olabarría, B. (1998). Para una historia del PIR o la Psicología Clínica como Especialidad Sanitaria: El proceso de institucionalización [Clinical psychology as a sanitary specialty: The process for institutionalization]. Revista de Psicopatología y Psicología Clínica, 3, 55-72. https://doi.org/10.5944/rppc.vol.3.num.1.1998.3856

Olabarría, B., \& García, M. A. (2011). Acerca del proceso de construcción de la Psicología Clínica en España como Especialidad Sanitaria [On the construction of clinical psychology in Spain as a health specialty]. Revista de Psicopatología y Psicología Clínica, 16, 223-245. https://doi.org/10.5944/rppc.vol.16.num.3.2011.10363

Paris, J. (2013). How the history of psychotherapy interferes with integration. Journal of Psychotherapy Integration, 23, 99-106. https://doi.org/10.1037/a0031419

Prado-Abril, J., Fernández-Álvarez, J., Sánchez-Reales, S., Youn, S. J., Inchausti, F., \& Molinari, G. (under review). La persona del terapeuta: Validación española del Cuestionario de Evaluación del Estilo Personal del Terapeuta (EPT-C) [The person of the therapist: Spanish validation of the Personal Style of the Therapist Questionnaire (PST-Q)].

Prado-Abril, J., Gimeno-Peón, A., Inchausti, F., \& Sánchez-Reales, S. (2019). Expertise, therapist effects and deliberate practice: The cycle of excellence. Papeles del Psicólogo, 40, 89-100. https://doi.org/10.23923/pap.psicol2019.2888

Prado-Abril, J., Sánchez-Reales, S., \& Aldaz-Armendáriz, J. A. (2014). Psicología Sanitaria: En busca de identidad [Health psychology: In search of identity]. Behavioral Psychology/Psicología Conductual, 22, 153-160.

Ruiz-Rodríguez, P., Cano-Vindel, A., Muñoz-Navarro, R., Wood, C. M., Medrano, L. A., Moretti, L. S., \& PsicAP Research Group (2018). Cost-effectiveness and cost-utility analysis of the treatment of emotional disorders in primary care: PsicAP Clinical Trial. Description of the substudy design. Frontiers in Psychology, 9, Article 281. https://doi.org/10.3389/fpsyg.2018.00281

Sánchez-Reales, S., Prado-Abril, J., \& Aldaz-Armendáriz, J. A. (2013). Psicología Clínica y Psicología General Sanitaria: Una aproximación constructiva [Clinical psychology and general health psychology: A constructive approach]. Behavioral Psychology/Psicología Conductual, 21, 189-200.

Sánchez-Reales, S., Prado-Abril, J., Inchausti, F., Fernández-García, X., Losada, C. J., \& AldazArmendáriz, J. A. (2017). From the White Paper on the qualification of the degree in psychology to the business of desperation: A quantitative analysis of psychology studies in Spain over the decade of 2005-2015. Papeles del Psicólogo, 38, 185-194. https://doi.org/10.23923/pap.psicol2017.2841

Truijens, F., Zühlke-van Hulzen, L., \& Vanheule, S. (2019). To manualize, or not to manualize: Is that still the question? A systematic review of empirical evidence for manual superiority in 
psychological treatment. fournal of Clinical Psychology, 75, 329-343.

https://doi.org/10.1002/jclp.22712

Van Broeck, N., \& Lietaer, G. (2008). Psychology and psychotherapy in health care: A review of legal regulations in 17 European countries. European Psychologist, 13, 53-63.

https://doi.org/10.1027/1016-9040.13.1.53

Vázquez-Barquero, J. L., \& García, J. (1999). Deinstitutionalization and psychiatric reform in Spain.

European Archives of Psychiatry and Clinical Neuroscience, 249, 128-135.

https://doi.org/10.1007/s004060050077

\section{EACLIPT}

Clinical Psychology in Europe (CPE) is the official journal of the European Association of Clinical Psychology and Psychological Treatment (EACLIPT).

\section{(4) \\ leibniz-psychology.org}

PsychOpen GOLD is a publishing service by Leibniz Institute for Psychology Information (ZPID), Germany. 